\title{
Enhancing the Civil and Environmental Engineering Capstone Program at Brigham Young University through On-Campus Internships and Graduate Student Mentors
}

Prof. E James Nelson, Brigham Young University

Mrs. Tatevik Christensen

Dr. Fernando S Fonseca, Brigham Young University

Fernando S. Fonseca obtained BS and MS degrees in Civil Engineering from Brigham Young University in 1987 and 1988, and a PhD in Structural Engineering from the University of Illinois at Urbana-Champaign. He is a Voting Member of MSJC main committee and of the Flexural, Shear, and Axial Loads Subcommittee. Since 1996 he has been on the faculty of Civil and Environmental Engineering at Brigham Young University. His research efforts are in Masonry Structures and Wood Structures.

Dr. A. Woodruff Miller, Brigham Young University

Received PhD from Stanford University in 1975. Professor in the Civil and Environmental Engineering Department at BYU for over 35 years. Department Chair from 2000 to 2006. 


\title{
Enhancing the Civil Engineering Capstone Program Through On- Campus Internships and Graduate Student Mentors
}

\begin{abstract}
Culminating educational experiences such as capstone design projects are playing an increasingly important role in meeting the educational objectives of Civil \& Environmental Engineering degrees. In recent years both the American Society of Civil Engineers (ASCE) and the Accreditation Board for Engineering and Technology (ABET) have placed a focus on the development of management, leadership and general business skills. Capstone programs offer an ideal environment that provides a synthesis of the fundamental technical engineering skills in developing a culminating design while creating an opportunity to focus on all of the professional practice skills necessary for students to become future leaders in their field.
\end{abstract}

Recognizing the opportunity to enhance development of these complimentary professional skills in the curriculum, the CE Department at Brigham Young University (BYU) has revamped its capstone class to provide experience in communication, project management, mentoring, leadership, and teamwork through real-world, hands-on projects. This evolving program engages graduate students as mentors and facilitators of industry sponsored projects. Undergraduate student teams have the opportunity to practice important collaboration skills while completing their design project independently as an on-campus internship.

Since the program was first piloted in 2010, fifteen different agencies and companies have sponsored more than thirty projects. This article describes the evolution of this innovative capstone experience and outlines the current program at BYU. It also presents a comparison between the BYU CE program and other universities.

\section{Defining the Capstone Course}

Capstone courses have become a widespread culminating experience in undergraduate engineering programs. They are largely the result of engineering programs seeking to better meet the needs of industry and have become so important that ABET requires universities to include them ${ }^{[1]}$. Nevertheless, capstone programs vary widely from school to school and a single definition that applies to all programs does not exist. According to Fairchild and Taylor ${ }^{[2]}$, capstone projects are "culminating experiences in which students synthesize the skills they have acquired, integrate cross-disciplinary knowledge, and connect theory and application in preparation for entry into a career." Durel ${ }^{[3]}$ offers another perspective stating that capstone can be seen as a "rite of passage or luminal threshold through which participants change their status from student to graduate. A capstone course should be a synthesis, reflection and integration, and a bridge or a real-world preparatory experience that focuses on the post-graduation future.”

Other definitions include, a crowning course or experience coming at the end of a sequence of courses with the specific objective of integrating a body of relatively fragmented knowledge into a unified whole ${ }^{[4]}$, and an experimental learning activity in which analytical knowledge gained from previous courses is joined with the practice of engineering in a final hands-on project which according to Wagener ${ }^{[5]}$ attempts to integrate, extend, critique, and apply the knowledge gained in the major. 
In today's world many professors and college graduates have observed that it takes more than technical expertise to be a successful professional. A wide range of nontechnical skills are essential: leadership, teamwork, problem solving, decision making, critical thinking, interpersonal communication, and management. These types of skills are often referred to as "soft skills." To help students develop both soft and technical skills, the objectives of a capstone course, project, or experience should typically include the following ${ }^{[6]}$ :

- Provide students an opportunity to synthesize knowledge from formal and informal learning and apply such knowledge to contemporary issues in the field

- Help prepare students for a successful career by providing experiences that enhance their labor market advantage

- Increase students' understanding of the "big picture” including ethical and social issues related to the field

- Help students understand the relevance of theory and research to practice

- Provide opportunities for teamwork and leadership

Because of the importance of capstone programs, ABET has delineated key components that these programs must have to be valid capstone experiences and to induce students to develop and apply both soft and technical skills. ABET has emphasized the need for engineering capstone courses to build teamwork, communication, and project based skills. Furthermore, ABET has mandated that capstone programs require students to work in multidisciplinary teams and design a system to meet desired needs within realistic constraints. In summary, ABET states that "students must be prepared for engineering practice through a curriculum culminating in a major design experience based on the knowledge and skills acquired in earlier course work and incorporating appropriate engineering standards and multiple realistic constraints.” [7]

\section{Survey of Civil Engineering Capstone Programs}

Although engineering capstone programs at different institutions may have many variations in their structure and operation, many of them share some basic components. According to a survey of several engineering disciplines conducted by Howe and Wilbarger ${ }^{[8]}$, many universities currently offer a one or two semester engineering capstone program with simultaneous class and project components. Although the survey included all engineering disciplines with only a few included CE programs, it provides a framework baseline from which a CE capstone program can be evaluated.

A popular arrangement for the surveyed engineering capstone programs is to group 4 to 6 students into a team and either assign projects to the teams or let the teams choose a project of their interest. The survey indicated that $71 \%$ of the projects are based on real-world problems. Other sources of projects are faculty research or design competitions. Schools usually participate in both real-world and academic projects by pairing faculty members with the student groups.

The educational institution usually finances the projects, though industry sponsorships have become more frequent. Sponsors are often granted some or all intellectual property rights, and sponsoring companies are becoming more involved with the students' teams. The survey estimated that the majority of engineering capstone industrial sponsors is contributing less than $\$ 500$ per project while the cost of completing the project is less than $\$ 1,000$. 
While most accredited universities have adopted capstone courses in their CE departments few have published details about their programs. One reason may be that many of these programs are relatively new and still evolving. About 50\% of CE departments have capstone programs that are less than 5 years old and only about $10 \%$ have programs older than 15 years.

The capstone program at the University of Utah ${ }^{[9]}$ has been evolving over the past 14 years. The course is based upon a proposed infrastructure project and the students manage the entire process including developing a preliminary engineering study as well as gathering county, city and state budget information that will be used for planning purposes. The students are divided into threeperson teams that are individually responsible for specific elements of the project. At Purdue University ${ }^{[10]}$ students work on projects that are either being considered or in the process of being designed. However, each student on a team completes the required design for one of the CE subspecialties (geotechnical, environmental/water resources, construction, and transportation).

At UC Berkeley ${ }^{[11]}$ there is a capstone course for each CE sub-discipline where teams are formed to address design, construction and maintenance of contemporary civil and environmental engineering systems. The capstone program at University of Washington ${ }^{[12]}$ is offered in 2 different courses. The first course is a design seminar that covers the fundamentals of integrated CE practice and design. The second course involves a capstone design project that can be in transportation and construction, structures and geotechnical, environmental, or water resources and hydrology depending on a student's interest. Real-world, community-based projects are assigned to the CE students at North Dakota State University ${ }^{[13]}$. By selecting community-based projects, the department strives to enrich the academic experience of the students and emphasize the relevance of the discipline to the society. The concept of service learning links community service to academic study so that each strengthens the other. The Seattle University ${ }^{[14]}$ CE capstone program has been in existence for the past 20 years and is unique because the projects are fully supported by industrial sponsors. Sponsors typically contribute from $\$ 5,000$ to $\$ 20,000$ depending on the organization's annual revenue. The funds are used to cover the faculty and staff time spent supervising the projects as well as any equipment needed for the projects. Each student team spends approximately 1000 hours on a project.

A review of these different capstone programs, where efforts appear to have been made to include deeper learning, indicate that they all incorporated the following elements:

- Only available to seniors as a graduation requirement.

- Teams either mentored by experienced engineering consultants who sponsored the projects or by faculty advisers.

- Real-world projects rather than academic or contrived projects. These projects could involve redesigning an existing project to determine if a better solution could be obtained, designing a new project, or working on a small portion of a larger project.

\section{Barriers to Implementation of Comprehensive Capstone Courses}

Our experience in developing a comprehensive capstone course shows that while it is ideal to have real-world projects sponsored and mentored by external advisers or faculty members, the 
availability and sustainability of these resources are major challenges and barriers to the implementation of such comprehensive capstone experiences, especially for larger programs. For example we found that while there are many local practicing engineers, including alumni, who have a desire to give back to the university community, the priority they place on responding to student questions relating to the project is understandably low relative to their dayto-day work. Similarly faculty charged with heavy teaching and research loads are not able to fully invest in the project and be available as often and as immediately as student teams need. Thus, if questions go unanswered, student teams become frustrated and the success of the design project and the student learning experience are jeopardized.

Our experience also shows that working on real world problems with their typical amount and variety of unknowns is beneficial but challenging to students. The time involvement required by course instructors is significant in developing the projects and insuring that they are of sufficient high quality to meet course objectives while being realistic in their demands on the students.

A key element in overcoming both of these barriers is funding. While some engineering capstone programs receive a monetary grant or donation in order to support their efforts, it appears that such finding is not common occurrence among civil engineering programs. Thus, faculty time and/or mentorship by external advisors must be done on a voluntary basis or by using resources allocated from already existing pools.

There is another possibility to overcome these barriers. In fact, a key element of the BYU program and its initial success, as subsequently outlined, has been the use of graduate students as mentors and liaisons between the project sponsors and the undergraduate students.

\section{Capstone Course at BYU CE Department}

\section{History}

In order to meet important educational objectives outlined by ABET and ASCE, the BYU CE department, similar to other CE departments, is trying to provide graduates with the best possible preparation for professional practice by enhancing the capstone program. Over the past 15-20 years, the BYU CE senior design has been through several transformations motivated by increased emphasis on culminating experiences as well as feedback from students and alumni. Early versions of the BYU CE capstone program included a one-hour engineering communications class and a design focused class. In the one-hour class students developed writing and presentation skills and discussed issues relative to business practice and public policy. Technical design objectives of the capstone program were met through the traditional reinforced concrete design class.

As ABET emphasized more rigor and integrated culminating experiences, the BYU CE department adopted a 3- credit class that combined the one-hour communication and professional practice class with a project, which was the design of a commercial shopping center. The project involved all the sub-disciplines: structural teams focused on the design of the store structure, geotechnical teams focused on the seismic analysis and retaining walls, transportation teams focused on parking and the flow of traffic to and from the shopping center, and water resources teams focused on drainage issues. Although the project provided a more integrated approach to the culminating design, it was still theoretical in nature without real-world constraints. 
The next iteration of the BYU CE capstone class changed the shopping center project to a teamselected project. Students were allowed to form their own teams of 3-5 students and choose their own projects. Many projects were innovative and based somewhat on real-world constraints, however others were overly simplified because students tended to stay within the realm of doing things that they already had skills to do. Students were responsible for defining the scope of work and they would avoid or work around issues that required additional research and training. While the new program was markedly better than the previous one, it still precluded the students from developing confidence in moving beyond the safety of known tools, methods, and analysis. Student's perception of the class improved but many students still felt the exercise was more of a "hurdle to jump through" than the kind of experience that genuinely prepared them for professional practice.

\section{Alumni Survey}

Recognizing the importance of developing business practice skills, the BYU CE Department offered a Master's of Engineering Management (MEM) from 1985 to 1995. Due to limited resources, the MEM degree was replaced in 1995 by a business management minor, which could be earned in conjunction with the Master's degree. This minor consisted of a 3-credit class in accounting, a 3-credit class in finance and a 3-credit elective from the business or public management school. In the fall of 2008 the business and accounting schools, which housed the management minor decided they could no longer offer the program. In response to evaluating the need to redefine and continue the management minor as well as assess other aspects of both the Master's and Bachelor's programs a comprehensive survey was conducted of all BYU CE alumni. Results from more than 450 respondents, shown in Figure 1, revealed that the department's greatest weakness was developing professional practice skills.

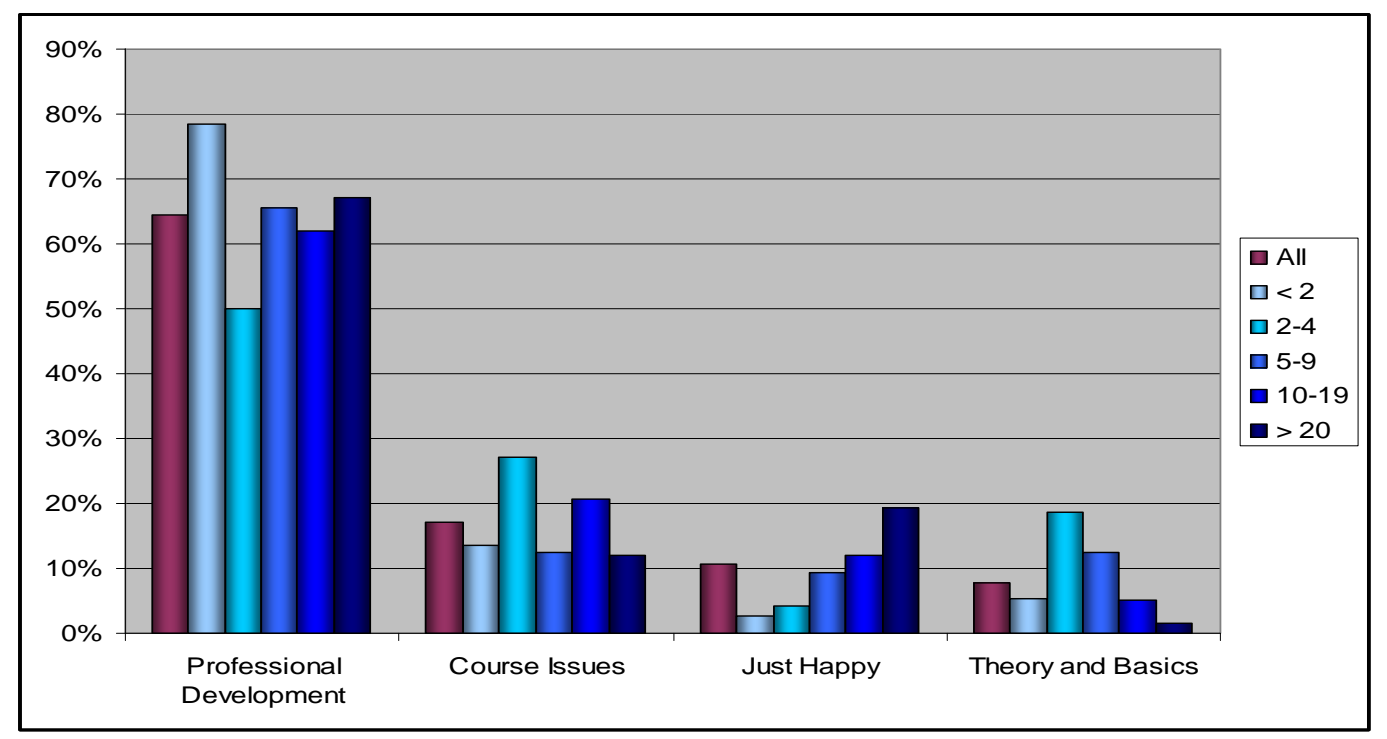

Figure 1. Suggested improvements grouped in years since graduation.

The open-ended questions survey asked respondents to indicate the greatest weakness of the department. For the purpose of understanding the answers better and establish possible trends, all responses were sorted into the four categories shown in Figure 1. Overwhelmingly the alumni indicated they were well prepared technically to practice civil engineering but not as well 
prepared for professional practice. They desired more experience working on real projects and managing projects and people along with a better understanding of developing work. They didn't understand how to work through public entities that often are the clients and/or the gatekeepers of large projects and desired to learn more about bonding and other mechanisms that fund civil infrastructure. The results of the survey supported the decision to develop a program to take the place of the former management minor at the graduate level. In doing so, and as a means of leveraging faculty resources we endeavored to define the graduate management and leadership experience in such a way that it could also strengthen the undergraduate capstone program.

\section{Program Overview}

The redesigned current CE capstone program at BYU spans two semesters and involves undergraduate and graduate students. Graduate students take classes in civil engineering business operations, project management, and leadership while mentoring teams of undergraduate capstone students. They work closely with project sponsors to acquire knowledge about the project and prepare requests for proposals with a rough scope of work during the fall semester. Undergraduate student teams, while learning the fundamentals of professional practice, develop proposals for the projects in response to the RFPs during fall semester. Each team then completes the work (in what is called on campus capstone internship) during the winter semester with the help of the assigned graduate student mentor, who is already familiar with the specific project. Project sponsors are asked to participate as a minimum in a kickoff meeting, evaluating progress at midterm and the final result, though they are free to be as involved in mentoring as much as their time and interests permit.

The main objective of the capstone program is to provide an opportunity for students to develop higher order thinking skills. Students learn how to analyze, evaluate, and create while learning the professional practice skills such economics, sustainability, project and people management, and client retention that are necessary for successful business practice.

At the end of the program, each student should:

1. Understand what engineering design is and be able to complete a design project to the satisfaction of a client.

2. Be able to apply the basic principles of project management so that quality work can be accounted for and completed on time.

3. Be able to integrate foundational engineering knowledge and experience.

4. Be able to participate both in leading and following roles as a team member on a highfunctioning team.

5. Take responsibility to learn and work independently; and also to seek outside help, advice, and feedback as needed to complete assigned work on the design project.

6. Have developed the attributes of a competent practicing civil engineer.

\section{Graduate Business Operations and Project Management and Leadership Classes}

To replace the vacated business management minor, a sequence of two courses for graduate students has been developed which goes beyond what is taught in the undergraduate capstone class. During the fall semester students learn about balance sheets, profitability, and the general business aspects of civil engineering firms. Much of the class is taught by alumni and other 
professionals who share their experiences in managing and owning a firm. The primary responsibility in terms of homework for the graduate students during the semester is to develop the RFPs for the undergraduate capstone class. Graduate students do so by working closely with the sponsors throughout the semester. There is one graduate student assigned to each project and during the semester each student learns enough about his or her project to be able to answer the questions the undergraduate students might have the following semester.

In the winter semester graduate students mentor the undergraduate teams during the execution of the projects while completing a separate class on project management and leadership. Graduate students act as mentor and client: they help undergraduate teams become high functioning and they answer the questions the teams may have about the projects. The client role is a critical element of the overall program, because while sponsors generally begin with the intention of being fully involved, the reality is that the capstone project holds a relatively low priority. The program is not sustainable if it takes days or weeks for a team to get an answer to its question.

\section{Undergraduate Capstone Professional Development and Internship Class}

As with the graduate classes emphasizing civil engineering professional practice, the undergraduate capstone experience is a two semester class. The fall semester is a one credit hour class that focuses on professional and business aspects of civil engineering organizations. Students are organized into teams of 3-5 students and the semester culminates with each team developing a proposal for one of the sponsored projects. During the winter semester student teams work on the project in an on campus, unpaid internship. Teams under the guidance of the graduate mentors organize themselves and work 6-8 hours weekly, including team organizational meetings, to complete the projects. An emphasis is given to team process as well as project completion through reading, discussions, and goal setting provided by the course instructor and facilitated by the graduate student mentor.

\section{Fall Course Outcomes, Capstone Professional Development}

1. Perform a triple bottom line analysis of an existing civil engineering project by evaluating social, environmental, and economic impact.

2. Learn about an existing civil engineering project by gathering and organizing information from published literature and the internet.

3. Understand the changing roles of the USA and other countries in the modern world in both contemporary society and civil engineering.

4. Explain the time value of money, construct cash-flow diagrams, and perform present worth and annual payments analyses of alternatives.

5. Outline tasks assigned to each team member for projects and reports to be completed in study abroad and culminating design courses.

6. Know the steps necessary to become a licensed professional engineer. Become committed to life-long learning.

7. Understand the procurement of engineering services and the associated legal and liability issues involved.

8. Understand the differing roles of practicing professionals, business managers, public administrators and others in project development.

9. Understand how to communicate effectively. 


\section{Winter Course Outcomes, Capstone Internship}

1. Understand and be able to apply conception, formulation, analysis, and search for solutions to civil engineering design problems.

2. Be able to integrate topics from various civil engineering disciplines to solve problems with multiple realistic constraints.

3. Be able to obtain and evaluate appropriate standards from databases, handbooks, experiments, and literature.

4. Be able to make estimates, assess reasonableness of solutions, and select appropriate engineering designs.

5. Be able to communicate with groups by giving effective, well-organized oral presentations.

6. Be able to communicate in a team environment.

7. Understand the proper use of visual aids in oral presentations.

8. Be able to compose professional documents in a clear, concise, and effective manner.

9. Understand the proper design and use of graphics in technical documents.

10. Function on multidisciplinary teams.

Capstone projects are solicited from private and public agencies. Since the program was begun, fifteen different agencies and companies have sponsored more than thirty projects. Table 1 provides an example of the kind of the projects that have been undertaken in 2012 and 2013.

Table 1. BYU CE Capstone Project Descriptions and Sponsoring Agencies for 2012 - 2013

\begin{tabular}{|c|c|c|}
\hline Project synopsis & Disciplines involved & Sponsoring agency \\
\hline $\begin{array}{l}\text { Prepare a speed/warrante analysis for the Daybreak } \\
\text { Parkway Couplet. }\end{array}$ & Transportation & Rio Tinto - Kennecott Utah Copper \\
\hline $\begin{array}{l}\text { Design a multi-use detention basin that provides flood } \\
\text { control, but can be used for recreation during dry weather. }\end{array}$ & $\begin{array}{c}\text { Water, } \\
\text { Environmental }\end{array}$ & Riverton City, Utah \\
\hline Design a footing for the Provo Tabernacle (temple). & Structural & $\begin{array}{l}\text { LDS Church Temple and Special } \\
\text { Projects Department, Utah }\end{array}$ \\
\hline $\begin{array}{l}\text { Evaluate the current and future level of services (LOS) for } \\
\text { one of the roundabouts in South Jordan, Utah. }\end{array}$ & Transportation & South Jordan City, Utah \\
\hline $\begin{array}{l}\text { Analyze building inventory data for Utah county to upgrade } \\
\text { the FEMA and State Hazus earthquake model. }\end{array}$ & Geotechnical & $\begin{array}{l}\text { Infrastructure Resilience } \\
\text { Department, URS Corporation, Utah }\end{array}$ \\
\hline $\begin{array}{l}\text { Provide the design of the relocation of a steel-framed structure } \\
\text { currently located in Riverton City, Utah }\end{array}$ & Structural & $\begin{array}{c}\text { Riverton City } \\
\text { department of engineering, Utah }\end{array}$ \\
\hline $\begin{array}{l}\text { Design a plan that changes two "tee" intersections into two } \\
\text { 4-way intersections, with a new connecting roadway between the two } \\
\text { new intersections. }\end{array}$ & Transportation & $\begin{array}{l}\text { Springville City } \\
\text { Public Works department, Utah }\end{array}$ \\
\hline Design a Bluffdale City stormwater conveyance. & $\begin{array}{l}\text { Water, } \\
\text { Environmental }\end{array}$ & Bluffdale City, Utah \\
\hline
\end{tabular}

\section{Program Sequence of Events}

A brief summary of the coordinated events of the program is given below:

- Each capstone team is assigned a graduate student mentor who guides them through the development of a design solution for the project. Graduate mentors serve as a liaison 
between the project sponsor and the team, and help the teams to meet the needs and wants of the sponsoring organization.

- Capstone teams respond to RFPs through a bidding process to obtain a project. Once the teams examine the potential projects, they bid on those projects by submitting a proposal. Teams register their intent to propose so that they have an opportunity to determine if there are other teams and how many are interested in proposing on the same projects. If only a single team responds to an RFP they will "win" that project, but if there is more than one team, the team with the highest ranked proposal wins that project. In either case teams must prepare a proposal which is scored and used as part of their grade evaluation. Teams also identify second and third choices from the projects and their proposal score is transferred to those projects for comparison against other unsuccessful proposals. There is the same number of projects as teams and each project is assigned to one of the teams.

- Team proposals describe why the team is the best suited to carryout and succeed in meeting the objectives of the given project. After the proposing window closes, each proposal is evaluated by a group made up of graduate students who have learned about job procurement, including the typical RFP/proposal/evaluation process. Graduate mentors and teams are notified of their respective assignments, and are asked to have a kick-off meeting with their project sponsors before the winter semester starts.

- Capstone team's progress is effectively monitored through regular contact among the project sponsor, the graduate mentor and the capstone team. Teams prepare a progress report weekly that is sent to both the graduate mentors and the project sponsors. To increase the likelihood of a successful project outcome, project sponsors and graduate mentors are asked to evaluate the project results by providing regular feedback to the teams.

- Capstone teams conclude their projects with a formal presentation to the university community and project sponsors through oral and poster presentations.

\section{Student Response}

During the transition from student-selected projects to sponsored projects there were some anxiety and uncertainty. Unlike other courses but much like actual project work, the end was not known from the beginning. Students were concerned that they would not be able to complete the work within the allotted time and reasonable effort and were generally uncomfortable with the uncertainties and new concepts they would be required to learn and implement. Instructors eased students' concerns and emphasized that, as in professional practice, if they worked the required internship hours, in fact they would accomplish much more than they thought possible.

Only a limited assessment can be made with anecdotal evidence of success from initial students' feedback. Given below are some of the students’ responses to the program.

- $\quad$ "I learned so much from this class. I learned how important it is to learn from other people. I had to talk with lots of different people during this project and I really learned how important experience is in engineering."

- $\quad$ "The project portion of this class was excellent. I loved that we were able to work on an actual project and go through all the steps of design. It was a good learning experience and I'm glad they've made the recent changes to this process.” 
- "Overall I feel that this course has been one of the more helpful courses I have had in the undergraduate courses for helping me to understand design, and how to work together as interdisciplinary group.”

- "The capstone project was an amazing learning experience. I appreciated learning about how to write reports and the like, as well as all I learned technically in our difficult project.”

- "The project aspect of this course was very beneficial. I never thought that I would get to work on a real-world project from concept through design during my education. I learned a great deal about working together in a team to accomplish something much larger than I can do on my own."

- "Great class! Besides an internship, this class is the only way students get to test themselves in solving real-world problems."

Combined with the additional learning graduate students obtain in professional practice, this integrated capstone program is hopefully meeting the need indicated in the results of the alumni survey. Results of a similar survey to be conducted in the future are needed to show if in fact students now feel more prepared to enter professional practice than they did previously.

\section{Conclusions}

Capstone is an important element of civil engineering programs and increased emphasis on professional practice development by ABET and ASCE has strongly influenced CE departments to strengthen culminating design experiences. Many departments across the country are improving their capstone programs to meet these demands by including such key elements as 1) real-world projects that stretch student technical and professional practice abilities, 2) teamwork emphasis, and 3) external sponsors and/or faculty mentors. While such elements are desirable and noble, their implementation requires significant resources.

The Civil and Environmental Engineering department at BYU has developed a unique program which combines further professional development practice of graduate students as mentors for undergraduate capstone teams. This program provides the key benefits of enhancing graduate student development while contributing to the solution of some of the key challenges in the undergraduate capstone program. Specifically graduate student mentors are able to assist in the transfer of information and act as "clients" to real-world sponsored projects. Such an arrangement relieves the pressure on sponsors and faculty advisers because graduate student mentors become part of the team and can answer most of the teams' questions. Graduate students also keep the team on track. Responses from graduate and undergraduate students who have participated in the program thus far suggest that the program is meeting the learning outcomes and student expectations. The program is still institutionally financed and finding ways to become self-sustaining remains a challenge.

\section{References}

1. Todd, R.C., Sorensen, C., \& Magleby, S. (1993). Designing a senior capstone course to satisfy industrial customers. Journal of engineering education, 82 (2), 92-100.

2. Fairchild, G. F., \& Taylor, T. G. (2000). Using business simulations and issue debates to facilitate synthesis in agribusiness capstone courses. Retrieved from http://ageconsearch.umn.edu/bitstream/36460/1/sp00fa02.pdf 
3. Durel, R. J. (1993). The capstone course: A rite of passage in teaching sociology. 223-225.

4. Dutson, A. J., Todd, R. H., Magleby, S. P., \& Sorensen, C. D. (1997). A review of literature on teaching engineering design through project-oriented capstone courses. Journal of engineering education, 17-28.

5. Wagener, T. C. (1993). The capstone course: Teaching sociology. 209-214.

6. Thomas, A. S. (1998). The business policy course: Multiple methods for multiple goals. Journal of management education 22, (4), 484-497.

7. ABET. Criteria for accrediting engineering technology programs, 2012 - 2013. Retrieved from http://www.abet.org/DisplayTemplates/DocsHandbook.aspx?id=3144

8. Howe, S., \& Wilbarger, J. (2006). National survey of engineering capstone design courses. Proc., ASEE annual conf., American Society of Engineering Education, Washington, D.C.

9. ASEE College Profiles. (2011). University of Utah. Retrieved from http://profiles.asee.org/profiles/5251/screen/13?school_name=university

10. Drnevich, V. P. (2001). Evolution of the civil engineering capstone design course at Purdue. ASCE, Retrieved from http://ascelibrary.org/doi/abs/10.1061/40590(274)13

11. ASEE College Profiles (2011). University of California, Berkeley. Retrieved from http://profiles.asee.org/profiles/5145/screen/13?school_name=University+of+California\%2C+Berkeley

12. ASEE. College Profiles (2011). University of Washington. Retrieved from http://profiles.asee.org/profiles/5332/screen/13?school_name=University+of+Washington

13. Padmanabhan, G., \& Dinesh, K. (2002). Using community-based projects in civil engineering capstone courses. ASCE, Retrieved from http://ascelibrary.org.erl.lib.byu.edu/doi/pdf/10.1061/(ASCE)10523928(2002)128:1(12)

14. Gnanapragasam, N. (2008). Industrially sponsored senior capstone experience: Program implementation and assessment. ASCE, Retrieved from http://ascelibrary.org.erl.lib.byu.edu/doi/pdf/10.1061/(ASCE)1052$\underline{3928(2008) 134: 3(257)}$ 